\title{
Efeito de Níveis de Suplementação sobre o Comportamento Ingestivo de Bezerras em Pastagem de Aveia (Avena strigosa Schreb.) e Azevém (Lolium multiflorum Lam.)
}

\section{Carolina Bremm¹, Marta Gomes da Rocha², João Restle ${ }^{3}$, Alcides Pilau ${ }^{4}$, Denise Baptaglin Montagner ${ }^{4}$, Fabiana Kellermann de Freitas ${ }^{4}$, Stefani Macari ${ }^{5}$, Denise Adelaide Gomes Elejalde ${ }^{5}$, Dalton Roso ${ }^{6}$, Juliano Roman ${ }^{5}$, Éverton Pujol Guterres ${ }^{5}$, Vagner Guasso da Costa 7 , Fábio Pereira Neves 5}

RESUMO - Foi avaliado o comportamento ingestivo de bezerras de corte submetidas a diferentes níveis de suplementação energética. Os níveis testados foram $(0 ; 0,5 ; 1,0 ; 1,5 \%$ do peso vivo), em pastagem de aveia preta (Avena strigosa Schreb.) e azevém (Lolium multiflorum Lam.). O suplemento foi farelo de trigo, fornecido diariamente às $14 \mathrm{~h}$. Para registro das atividades de pastejo, ruminação, ócio e permanência no cocho, adotou-se a observação visual, feita a cada dez minutos, durante 24 horas, em quatro datas. Para cada nível de suplementação, foram observados seis animais dos grupos genéticos Charolês, 3/4 Charolês/Nelore e 5/8 Nelore/ Charolês, com aproximadamente oito meses de idade e peso inicial de $158 \mathrm{~kg}$. Os animais que receberam suplementação diminuíram o tempo de pastejo em relação aos não-suplementados, sem alteração no consumo estimado de forragem. Os animais que receberam suplementação a 1,5\% do PV permaneceram mais tempo no cocho, aumentando a freqüência de retorno ao cocho nos maiores níveis de suplementação. Os níveis de suplementação não interferiram nos tempos de ruminação e ócio.

Palavras-chave: Charolês, farelo de trigo, pastejo contínuo

\section{Ingestive Behavior of Beef Heifers Grazing Oat (Avena strigosa Schreb) and Ryegrass (Lolium multiflorum Lam) Pasture under Supplementation Levels}

\begin{abstract}
The ingestive behavior of beef heifers when submitted to different energy supplementation levels was evaluated. Heifers grazing Italian ryegrass (Lolium multiflorum Lam.) and black oat (Avena strigosa Schreb) pasture, were supplemented with wheat bran, supplied daily at 2 p.m. at levels of $0 ; 0.5 ; 1.0 ; 1.5 \%$ of live weight. The activities of grazing, rumination, idle and trough permanence, were recorded by visual observation, at a ten minute intervals, in four periods of 24 hours. For each supplementation level were allocated six animals of genetic groups Charolais, 3/4Charolais/Nellore and 5/8Nellore/Charolais, with eight months of age and $158 \mathrm{~kg}$ of initial weight. Supplemented animals reduced grazing time, compared with no supplemented animals, without changing estimated pasture consumption. Animals supplemented at $1.5 \%$ of live weight, spent longer time at trough and showed a higher visiting frequency. The supplementation levels did not interfere in rumination and idle times.
\end{abstract}

Key Words: Charolais, continuous grazing, wheat bran

\section{Introdução}

$\mathrm{O}$ crescimento da agricultura tem modificado a paisagem do Rio Grande do Sul, em áreas tradicionalmente destinadas à pecuária extensiva. Com a valorização das terras, há necessidade de mudança no modelo de produção da pecuária de corte, na direção de um sistema mais intensivo. Este sistema é caracterizado pela utilização de alta carga animal e pelo uso da suplementação (Rearte \& Pieroni, 2001). Essa intensificação altera o comportamento ingestivo dos animais em pastejo e o seu conhecimento pode ser útil no estabelecimento de novas práticas de manejo, visando maior eficiência do sistema produtivo (Euclides, 1985; Galli et al., 1996).

Quando os animais são suplementados, novas variáveis interferem no consumo de nutrientes e estão associadas às relações de substituição de forragem por suplemento e/ou à adição no consumo total de matéria seca, que mudam conforme as características da base forrageira e do suplemento (Hodgson, 1990). Entre os resultados, destaca-se a

\footnotetext{
${ }_{1}^{1}$ Aluna do curso de Graduação em Zootecnia - UFSM, Bolsista FAPERGS. carobremm@terra.com.br

${ }^{2}$ Eng. Agr. Dra. Bolsista do CNPq. Professora Adjunto - Departamento de Zootecnia - UFSM. tata@pro.via-rs.com.br

${ }^{3}$ Eng. Afe. PhD. Professor visitante/CNPq - Depto. Produção-UFG. E.mail: jorestle@terra.com.br

${ }^{4}$ Zoot. Aluno do curso de Pós Graduação em Zootecnia - UFSM. setorforrageiras@bol.com.br

5 Alunos dos cursos de Graduação em Agronomia, Medicina Veterinária e Zootecnia -UFSM. setorforrageiras@bol.com.br

${ }^{6}$ Aluno do curso de Graduação em Agronomia -UFSM, Bolsista FAPERGS. setorforrageiras@bol.com.br

${ }^{7}$ Aluno do curso de Graduação em Zootecnia -UFSM, Bolsista CNPq. setorforrageiras@bol.com.br
} 
mudança no tempo de pastejo (Karsli, 2001), podendo diminuí-lo (Hess et al., 1992; Bonfim et al., 2000) ou aumentá-lo em relação aos animais não-suplementados (Adams, 1985).

Objetivou-se, neste trabalho, avaliar o comportamento ingestivo de bezerras de corte mantidas em pastagem cultivada de aveia (Avena strigosa Schreb) e azevém (Lolium multiflorum Lam.), recebendo diferentes níveis de suplementação de farelo de trigo.

\section{Material e Métodos}

O experimento foi desenvolvido no Departamento de Zootecnia da Universidade Federal de Santa Maria, situada na Depressão Central do Rio Grande do Sul. O clima da região é do tipo Cfa (subtropical úmido), segundo a classificação de Köppen (Moreno, 1961).

As observações do comportamento animal foram realizadas em oito piquetes com pastagem de aveia preta (Avena strigosa Schreb.) + azevém (Lolium multiflorum Lam.), com área total de 7,7 hectares, com duas repetições de área por tratamento. Dentro de cada piquete, foram observados três animais-teste, cada um representando os seguintes grupos genéticos: Charolês, 3/4 Charolês/Nelore e 5/8 Nelore/Charolês, com aproximadamente oito meses de idade e peso médio inicial de $158 \mathrm{~kg}$. Os animais foram identificados por meio de tatuagens e brincos numerados. Por ocasião das avaliações do comportamento, os animais-teste eram pintados para facilitar sua identificação.

Os níveis de suplementação estudados foram: SS - sem suplemento; S0,5 - suplementação de 0,5\% do peso vivo (PV); S1,0 - suplementação de 1,0\% do PV; S1,5 - suplementação de $1,5 \%$ do PV. O suplemento utilizado foi farelo de trigo, fornecido diariamente às $14 \mathrm{~h}$, em cochos de madeira.

A aveia e o azevém foram implantados (08/05/2002) pelo método de preparo mínimo, com 90 e $35 \mathrm{~kg} / \mathrm{ha} \mathrm{de}$ aveia preta e azevém, respectivamente. Foram utilizados $300 \mathrm{~kg} / \mathrm{ha}$ da fórmula 05-20-20 como adubação de base e $130 \mathrm{~kg} / \mathrm{ha}$ de nitrogênio na forma de uréia, em cobertura, parcelado em três aplicações.

O sistema de pastejo foi contínuo com lotação variável, empregando-se a técnica put-and-take (Mott \& Lucas, 1952) e teve duração de 115 dias (10/07 a $02 / 11 / 2002)$. A massa de forragem (MF) pretendida foi $1000,1200,1400$ e $1600 \mathrm{~kg}$ de MS/ha nos diferentes períodos de utilização.

A MF foi determinada no início do período de pastejo e, posteriormente, a cada 14 dias, pela técnica de dupla amostragem (Wilm et al., 1944). Em cada repetição, foram realizados cinco cortes rente ao solo e 20 estimativas visuais. Para a determinação da taxa de acúmulo diária (TAD), expressa em $\mathrm{kg} / \mathrm{ha}$, foram utilizadas três gaiolas de exclusão ao pastejo por repetição, conforme Klingmann et al. (1943). A oferta de forragem (kg de MS/100 kg de PV) foi calculada dividindo-se a disponibilidade de forragem diária $(\mathrm{MF} / 28$ dias + TAD) pela carga média animal do período. A medição da altura do pasto foi realizada a cada estimativa da MF, medindo-se a distância do solo até a altura média do dobramento das folhas dentro do quadrado.

O teor de matéria seca (MS) foi determinado a partir de amostras colhidas em cada avaliação de dupla amostragem, por repetição. As amostras foram pesadas e secas em estufa com circulação forçada a $65^{\circ} \mathrm{C}$, por no mínimo 72 horas, até peso constante.

$\mathrm{O}$ valor nutritivo da forragem foi estimado em análise laboratorial de amostras de forragem colhidas por meio de simulação de pastejo (Euclides et al., 1992). As amostras foram pesadas e secas em estufa a $65^{\circ} \mathrm{C}$, por 72 horas, após processamento em moinho tipo Wiley, e encaminhadas para análise. Os parâmetros avaliados foram: proteína bruta $(\mathrm{PB})$, de acordo com as técnicas descritas pela AOAC (1984), e digestibilidade in vitro da matéria orgânica (DIVMO), segundo Tilley \& Terry (1963).

As avaliações de comportamento foram feitas em quatro períodos contínuos de 24 horas, respectivamente, nos dias 03 e 04/08, 30 e 31/08, 27 e 28/09 e 31/10 e 01/11, a partir de observação visual (Jamieson \& Hodgson, 1979a). A cada dez minutos foram anotadas as atividades de pastejo, ócio, ruminação e permanência no cocho. O tempo gasto pelos animais na seleção e apreensão da forragem, incluindo os curtos espaços de tempo utilizados no deslocamento para a seleção da forragem, foi considerado tempo de pastejo (Hancock, 1953), enquanto o tempo de ócio foram os períodos de descanso (Forbes, 1988) e o tempo de ruminação correspondeu ao período de cessação do pastejo e da realização de mastigação. $\mathrm{O}$ tempo de permanência no cocho foi o tempo despendido pelo animal no consumo de suplemento e no local onde era servido o suplemento. Foram utilizados oito avaliadores, divididos em plantões de quatro horas, ficando cada responsável pela observação dos animais-teste de dois piquetes.

Para determinação das perdas de forragem, foram demarcados, com duas estacas, oito pontos amostrais 
alocados em três transectas, em cada repetição. Em cada ponto amostral, em cada avaliação, foi colocado um quadrado com área de $0,0625 \mathrm{~m}^{2}$ para coleta da forragem considerada não-aproveitável pelos animais, constituída por material morto, senescente e danificado pelo pisoteio e pastejo (Hillesheim, 1997).

Para o cálculo do consumo diário de MS por período, foi subtraído da produção total de MS/ha a diferença entre a forragem disponível no final e no início de cada período experimental e as perdas de forragem ocorridas ao longo do período de pastejo. Dividindo o consumo estimado de MS/ha pela carga animal média, obteve-se o consumo estimado de MS, em \% do PV.

Durante o terceiro e quarto períodos, nos mesmos dias de avaliação do comportamento animal, foram registradas as taxas de bocados dos animais-teste de cada tratamento, sendo estimada pelo tempo gasto pelo animal para realizar 20 bocados (Hodgson, 1982). Para o cálculo do tamanho de bocado, dividiu-se o consumo diário de forragem pelo total de bocados diários (taxa de bocados $\mathrm{x}$ tempo de pastejo; Jamieson \& Hodgson, 1979b).

O ganho de peso médio diário (GMD) dos animais foi obtido pela diferença entre peso final e inicial dos animais-teste, em cada período experimental, dividida pelo número de dias do período. A carga animal (CA) por período correspondeu à soma do peso médio dos animais-teste. A este valor foi adicionado o peso médio dos animais reguladores multiplicado pelo número de dias que permaneceram na repetição, dividido pelo número de dias do período de pastejo.

As taxas de substituição e adição do consumo de suplemento sobre o consumo de forragem foram estimadas a partir do cálculo proposto por Hodgson (1990), em que: substituição = (consumo de forragem dos animais não-suplementados - consumo de forragem dos animais que recebem suplementação)/consumo de suplemento*100; adição $=($ consumo total de MS dos animais suplementados - consumo de forragem dos animais não suplementados)/consumo de suplemento* 100 .

$\mathrm{O}$ delineamento experimental adotado foi o inteiramente casualizado com duas repetições. O modelo matemático referente à análise dos parâmetros estimados foi:

$$
Y_{i j k}=\mu+N S_{i}+P_{j}+R_{k}(N S)_{i}+(N S * P)_{i j}+E_{i j k l}
$$

em que $\mathrm{Y}_{\mathrm{ijkl}}=$ variáveis dependentes; $\mu$ = média de todas as observações; $\mathrm{NS}_{\mathrm{i}}=$ efeito do i-ésimo nível de suplementação; $\mathrm{P}_{\mathrm{j}}=$ efeito do $\mathrm{j}$-ésimo período; $\mathrm{R}_{\mathrm{k}}$ $(\mathrm{NS})_{\mathrm{i}}=$ efeito da k-ésima repetição dentro do i-ésimo nível de suplementação (erro A); $\mathrm{NS}^{*} \mathrm{P}_{\mathrm{ij}}=$ efeito de interação entre o i-ésimo nível de suplementação e o j-ésimo período; $\mathrm{E}_{\mathrm{ijk}}=$ erro experimental (erro B).

Em caso de interação NS*P, foi realizado teste de regressão polinomial até terceira ordem a $5 \%$, sendo considerada a de maior coeficiente de determinação $\left(\mathrm{R}^{2}\right)$. Os dados foram submetidos à análise de variância e ao teste $\mathrm{F}$ a $5 \%$ de significância e, quando detectadas diferenças entre os tratamentos, efetuou-se a comparação de médias. As variáveis foram estudadas por intermédio do programa estatístico SAS (1996).

\section{Resultados e Discussão}

Na Tabela 1 encontram-se os valores médios de massa de forragem (MF), altura do pasto, oferta de forragem, matéria seca (MS), proteína bruta $(\mathrm{PB})$ e digestibilidade in vitro da matéria orgânica (DIVMO) da forragem colhida por simulação de pastejo. As variáveis supracitadas não foram influenciadas ( $\mathrm{P}>0,05)$ pelos níveis de suplementação.

A MF aumentou de $977 \mathrm{~kg} / \mathrm{ha}$ de MS para $1.590 \mathrm{~kg} / \mathrm{ha}$ de MS, no decorrer do período de pastejo, sendo em média de $1201 \mathrm{~kg} / \mathrm{ha}$ de MS. A altura média do pasto, nos quatro períodos, foi de $15 \mathrm{~cm}$, com menores valores no segundo período de avaliação $(\mathrm{P}<0,01)$. A oferta de forragem média foi de $10 \mathrm{~kg}$ de MS/100 kg de PV e variou de 8 a $12 \mathrm{~kg}$ de MS/100 kg de PV durante o período de pastejo, com maiores valores no segundo período $(\mathrm{P}<0,01)$. Segundo Gibb \& Treacher (1976), esta oferta não é limitante ao consumo animal.

A MS média de todo período de pastejo foi de $15,75 \%$ e foi mais elevada no quarto período de avaliação $(\mathrm{P}<0,01)$. O teor médio de $\mathrm{PB}$ na forragem aparentemente consumida foi de $21,1 \%$, sendo maior $(24,8 \%)$ e menor $(14,6 \%)$ no segundo e quarto períodos, respectivamente. A DIVMO média foi de $54 \%$ e não diferiu entre períodos $(\mathrm{P}>0,01)$.

Constam na Tabela 2 os valores médios do tempo de pastejo (TP) de bezerras de corte recebendo diferentes níveis de suplementação energética.

O tempo de pastejo variou dentro dos períodos do dia. Animais pastejaram por mais tempo no período de 6 às $18 \mathrm{~h}$ e dedicaram menor tempo ao pastejo entre 18 e 6 h $\quad(\mathrm{P}<0,05)$, confirmando a informação de 
Tabela 1 - Valores médios de massa de forragem, altura do pasto, oferta de forragem, porcentagens de matéria seca e de proteína bruta e digestibilidade in vitro da matéria orgânica de bovinos sob pastejo em uma pastagem de aveia ( $A$. strigosa) e azevém (L. multiflorum), recebendo suplementação energética

Table 1 - Mean values of herbage mass, pasture height, forage on offer, percentages of dry matter, crude protein and in vitro organic matter digestibility in black oat (A. strigosa) and Annual ryegrass (L. multiflorum) pasture under grazing by beef cattle fed energy supplementation

Parâmetro da pastagem

Período Média

Parameter of pasture

Period

Mean

\begin{tabular}{lccccc} 
& $21 / 07$ a & $18 / 08$ a & $15 / 09$ a & $13 / 10$ a & \\
& $17 / 08$ & $14 / 09$ & $12 / 10$ & $02 / 11$ & \\
\hline Massa de forragem (kg/ha MS) & $977 \mathrm{c}$ & $1112 \mathrm{c}$ & $1360 \mathrm{~b}$ & $1590 \mathrm{a}$ & 1201
\end{tabular}

Forage mass ( $\mathrm{kg} / \mathrm{ha}$ of $\mathrm{DM})$

Altura (cm)

Height $(\mathrm{cm})$

Oferta de forragem $(\mathrm{kg} \mathrm{MS} / 100 \mathrm{~kg} \mathrm{PV})$
Forage on offer ( $\mathrm{kg}$ of $D M / 100 \mathrm{~kg} \mathrm{LW})$

Matéria seca (\%)

Dry matter (\%)

Proteína bruta $(\%)$

Crude protein (\%)

$\operatorname{DIVMO}(\%)$

$16 \mathrm{a}$

$12 \mathrm{~b}$

$15 \mathrm{a}$

$16 \mathrm{a}$

15

$9 \mathrm{~b}$

$12 \mathrm{a}$

$8 b$

$8 b$

10

IVMOD (\%)

$\begin{array}{ccccc}14,9 \mathrm{~b} & 14,0 \mathrm{~b} & 13,7 \mathrm{~b} & 23,2 \mathrm{a} & 15,7 \\ 18,0 \mathrm{c} & 24,8 \mathrm{a} & 21,6 \mathrm{~b} & 14,6 \mathrm{~d} & 21,1 \\ 56,0 & 49,0 & 57,0 & 47,0 & 54,0\end{array}$

Médias, na mesma linha, seguidas por letras distintas, diferem $(P<0,05)$ pelo teste $F$.

Means, in the same line, followed by different letters, differ $(P<.05)$ by $F$ test.

Tabela 2 - Médias estimadas de tempo de pastejo (minutos) de bezerras de corte em pastagem de aveia ( $A$. strigosa) e azevém ( $L$. multiflorum), recebendo suplementação energética

Table 2 - Estimated means of grazing time (minutes) of beef heifers fed energy supplementation in black oat (A. strigosa) and Annual ryegrass (L. multiflorum) pasture

\begin{tabular}{|c|c|c|c|c|c|}
\hline \multicolumn{6}{|c|}{$\begin{array}{l}\text { Tempo de pastejo, minutos } \\
\text { Grazing time, minutes }\end{array}$} \\
\hline \multirow{3}{*}{$\begin{array}{l}\text { Tratamento } \\
\text { Treatment }\end{array}$} & \multirow{2}{*}{\multicolumn{4}{|c|}{$\begin{array}{c}\text { Horário } \\
\text { Timetable } \\
\end{array}$}} & \multirow{3}{*}{$\begin{array}{l}\text { Total } \\
\text { Total }\end{array}$} \\
\hline & & & & & \\
\hline & 06-12 & $12-18$ & $18-24$ & $24-06$ & \\
\hline SS & 169,16 & 204,57 & 79,58 & 66,66 & $519,97 \mathrm{~A}$ \\
\hline S0,5 & 135,83 & 145,83 & 55,00 & 67,49 & $404,13 \mathrm{~B}$ \\
\hline $\mathrm{S} 1,0$ & 134,78 & 155,41 & 64,58 & 46,66 & $401,43 B$ \\
\hline $\mathrm{S} 1,5$ & 95,95 & 111,66 & 56,25 & 47,08 & $310,93 \mathrm{~B}$ \\
\hline Média & $133,93 \mathrm{a}$ & $154,37 \mathrm{a}$ & $63,85 b$ & $56,97 \mathrm{~b}$ & \\
\hline Mean & & & & & \\
\hline
\end{tabular}

Médias, na mesma linha, seguidas por letras distintas, diferem $(P<0,05)$ pelo teste $F$.

Means, in the same line, followed by distinct letters, differ $(P<.05)$ by $F$ test.

Médias, na mesma coluna, seguidas por letras distintas, diferem $(P<0,05)$ pelo teste $F$.

Means, in the same column, followed by distinct letters, differ $(P<.05)$ by $F$ test. 
Stobbs (1970) de que o tempo de pastejo noturno representa uma pequena percentagem do tempo total de pastejo diário e contribui minimamente para o consumo de forragem.

Animais não-suplementados pastejaram significativamente por mais tempo que os animais suplementados. Quando exclusivamente em pastagem, o TP dos animais foi superior 22,3, 22,8 e 40,2\% ao TP dos animais que receberam suplemento a 0,5 , 1,0 e $1,5 \%$ do PV, respectivamente, correspondendo a 115,84, 118,54 e 209,04 minutos a mais de TP. A redução no TP com o consumo de suplementos está de acordo com dados de Krysl \& Hess (1993), em revisão sobre a influência de suplementação energética sobre o tempo de pastejo. Estes autores concluíram que, aumentando o nível de grãos utilizados como suplemento, diminui o tempo de pastejo dos animais, o que não aconteceu neste trabalho, pois níveis de 0,5 ; 1 e $1,5 \%$ resultaram em tempos de pastejo semelhantes. Patiño Pardo et al. (2003) também verificaram decréscimo progressivo no tempo de pastejo diurno em animais suplementados, à medida que foi aumentada a oferta de concentrado.

O TP de 519,97 minutos/dia dos animais que não receberam suplementação pode ser considerado alto quando comparado ao tempo médio de pastejo de 419 minutos/dia observado em forrageiras temperadas (Chacon et al., 1976). O TP médio, nos quatro níveis de suplementação, foi de 409,12 minutos, muito similar ao tempo de pastejo de 420 minutos observado por Stobbs (1970) em pastagem de alta qualidade, sem suplementação.

Contrariando a afirmação de Krysl \& Hess (1993) de que fatores como temperatura e manejo da pastagem influenciam o tempo diário de pastejo, não houve interação entre níveis de suplementação e períodos ( $\mathrm{P}>0,05)$, com temperaturas médias, nas quatro datas das avaliações, respectivamente, de 13,$75 ; 12,45$; 22,6 e $18,1^{\circ} \mathrm{C}$. Também Poli et al. (2001) registraram que o comportamento de pastejo é influenciado pelas características da pastagem e por sua mudança no decorrer do ciclo das forrageiras.

Na Figura 1, pode ser visualizada a distribuição percentual das bezerras-teste em pastejo, em cada um dos tratamentos avaliados. Houve maior concentração de animais em pastejo nos horários correspondentes ao amanhecer ( $7 \mathrm{~h}$ ) e entardecer (18 h). Entre os animais não-suplementados, houve grande concentração de animais em pastejo de 12 até as 18 h, ao
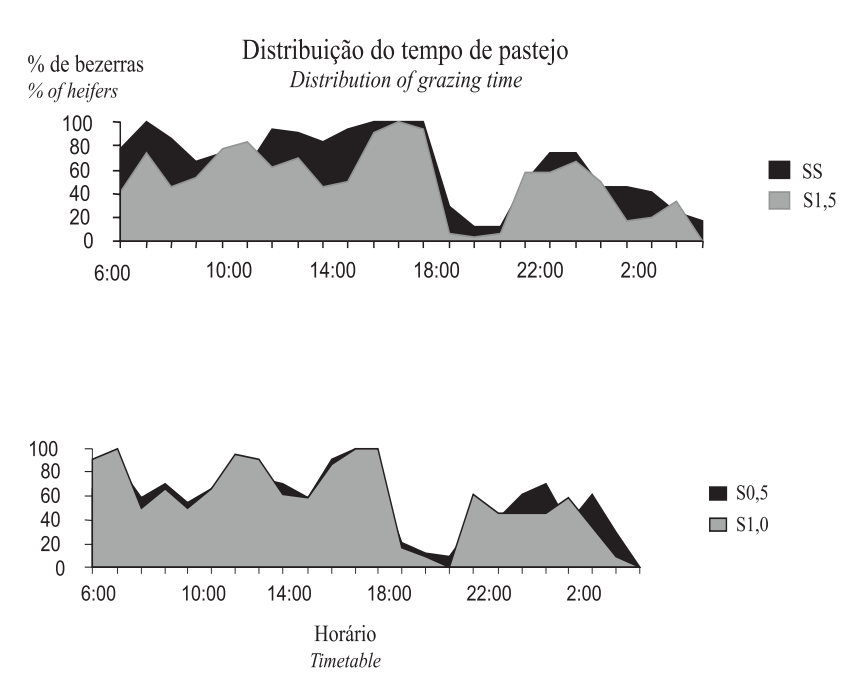

Figura 1 - Distribuição das bezerras-teste na atividade de pastejo nos tratamentos sem suplementação e com suplementação (SS - sem suplementação; S0,5 - suplementação a $0,5 \%$ do PV; S1,0 suplementação a $1,0 \%$ do PV; S1,5 suplementação a 1,5\% do PV).

Figure 1 - Distribution of tester heifers in grazing activity to the treatments without and with supplements (SS without supplement; S0.5 - supplementation of $0.5 \%$ live weight; 51.0 - supplementation of $1.0 \%$ live weight; S1.5 - supplementation of $1.5 \%$ live weight).

passo que, entre os animais que receberam suplemento em menor proporção, observou-se concentração no horário anterior ao fornecimento do suplemento, realizado diariamente às 14 horas. Polli \& Lobato (1984) e Nardon et al. (1987) também relataram maior intensidade de pastejo ao amanhecer e ao entardecer.

Constam, na Tabela 3, os valores de consumo estimado de forragem (CF) nos diferentes níveis de suplementação.

O maior TP observado nos animais que não receberam suplementação não correspondeu ao maior consumo estimado de forragem, pois não houve diferença para este parâmetro nos diferentes níveis de suplementação ( $\mathrm{P}>0,05)$. Resultados de Forcherio et al. (1992) e Sunvold et al. (1991) comprovaram que quando suplementos à base de fibra rapidamente digestível são consumidos, como é o caso do farelo de trigo, reduções no consumo de forragem não são tão evidentes quando comparadas com suplementos à base de amido. Não houve interação entre nível de suplemento e período $(\mathrm{P}>0,05)$. O CF foi maior $(\mathrm{P}<0,05)$ no período de $18 / 08$ a 14/09, provavelmente em decorrência da maior participação de azevém em 
início de estádio vegetativo na pastagem e da preferência deste pelos animais, revelando maior eficiência de pastejo neste período, visto que o tempo de pastejo dos animais-teste não diferiu entre os períodos de observação. A média estimada de $\mathrm{CF}$, nos quatro períodos, foi de 3,$8 ; 3,6 ; 2,8$ e $3,1 \%$ do $\mathrm{PV}$, respectivamente para as bezerras $\mathrm{SS} ; \mathrm{S} 0,5 ; \mathrm{S} 1,0$ e S1,5, superior ao consumo de $2,5 \%$ do $\mathrm{PV}$ recomendado pelo NRC (1996) para animais desta categoria. Os tamanhos médios de bocado das bezerras-teste de cada tratamento foram de $0,24,0,23,0,21$ e $0,36 \mathrm{~g}$ $\mathrm{MO} /$ bocado, respectivamente, para SS, S0,5, S1,0 e S1,5, dentro da amplitude relatada por Stobbs (1973) de 0,05 a $0,80 \mathrm{~g} \mathrm{MO} /$ bocado, variando conforme a disponibilidade e acessibilidade da forragem.
As taxas de substituição (Tabela 4) variaram de 0 a 2,8, sendo estes extremos encontrados quando os animais receberam $0,5 \%$ do $\mathrm{PV}$ em suplemento.

A taxa de substituição média encontrada para os níveis $0,5,1$ e $1,5 \%$ do PV, respectivamente, de $0,4,1$ e $0,46 \mathrm{~kg}$ de forragem para cada $\mathrm{kg}$ de suplemento fornecido, é semelhante à taxa de substituição de 0,5 a 0,9 kg relatada por Rocha (1999). A carga animal (CA) média do período de pastejo foi $858 ; 864 ; 1067$ e $1135 \mathrm{~kg} / \mathrm{h}$ a de PV em SS, S0,5, $\mathrm{S} 1,0$ e S1,5, respectivamente (Pilau et al., 2004). O incremento em CA foi praticamente nulo $(0,7 \%)$ no nível S0,5, enquanto, em S1,0 e S1,5, foi de 24,3 e $32,3 \%$, respectivamente, em relação ao uso exclusivo de pastagem.

Tabela 3 - Consumo estimado de forragem (MS), expresso em \% do PV, de bezerras de corte recebendo diferentes níveis de suplemento em pastagem de aveia ( $A$. strigosa) e azevém (L. multiflorum)

Table 3 - Estimated forage consumption, expressed in \% of LW, from beef heifers receiving different levels of supplement in oat (A. strigosa) and Italian ryegrass (L. multiflorum) pasture

\begin{tabular}{|c|c|c|c|c|c|}
\hline & & $\begin{array}{l}\text { umo esti } \\
\text { imated fo }\end{array}$ & $\begin{array}{l}\text { o de forr } \\
\text { consumpt }\end{array}$ & & \\
\hline Tratamento & & & & & Média \\
\hline Treatment & & & & & \\
\hline & $21 / 07 a$ & $18 / 08 \mathrm{a}$ & $15 / 09 a$ & $13 / 10 a$ & \\
\hline & $17 / 08$ & $14 / 09$ & $12 / 10$ & $02 / 11$ & \\
\hline SS & 3,1 & 5,3 & 3,3 & 3,5 & 3,8 \\
\hline So,5 & 3,7 & 5,9 & 2,8 & 2,1 & 3,6 \\
\hline $\mathrm{S} 1,0$ & 2,5 & 4,8 & 2,3 & 1,7 & 2,8 \\
\hline $\mathrm{S} 1,5$ & 2,9 & 4,9 & 1,6 & 3,3 & 3,1 \\
\hline Média & $3,0 \mathrm{~b}$ & $5,2 \mathrm{a}$ & $2,5 b$ & $2,6 b$ & \\
\hline Mean & & & & & \\
\hline
\end{tabular}

Médias, na mesma linha, seguidas por letras distintas, diferem $(P<0,05)$ pelo teste $F$.

Means, in the same line, with distinct letters, differ $(P<.05)$ by $F$ test.

Tabela 4 - Taxa de substituição do consumo de forragem pelo consumo de suplemento em pastagem de aveia ( $A$. strigosa) e azevém ( $L$. multiflorum) de bezerras de corte recebendo diferentes níveis de suplemento

Table 4 - Substitution rate of forage consumption toward supplement consumption from beef heifers receiving different levels of supplement in oat (A. strigosa) and Italian ryegrass (L. multiflorum) pasture

\begin{tabular}{|c|c|c|c|c|c|}
\hline \multirow{5}{*}{$\begin{array}{l}\text { Tratamentos } \\
\text { Treatments }\end{array}$} & \multicolumn{4}{|c|}{$\begin{array}{c}\text { Taxa de substituição } \\
\text { Substitution rate }\end{array}$} & \multirow{5}{*}{$\begin{array}{l}\text { Média } \\
\text { Mean }\end{array}$} \\
\hline & \multirow{2}{*}{\multicolumn{4}{|c|}{$\begin{array}{l}\text { Períodos } \\
\text { Periods }\end{array}$}} & \\
\hline & & & & & \\
\hline & $21 / 07 \mathrm{a}$ & $18 / 08 \mathrm{a}$ & $15 / 09 a$ & $13 / 10 \mathrm{a}$ & \\
\hline & $17 / 08$ & $14 / 09$ & $12 / 10$ & $02 / 11$ & \\
\hline S0,5 & 0 & 0 & 1,00 & 2,80 & 0,40 \\
\hline $\mathrm{S} 1,0$ & 0,60 & 0,50 & 1,00 & 1,80 & 1,00 \\
\hline $\mathrm{S} 1,5$ & 0,13 & 0,26 & 1,10 & 0,13 & 0,46 \\
\hline
\end{tabular}


A suplementação energética para animais em pastejo tem sido empregada para aumentar os nutrientes da dieta pela adição dos nutrientes contidos no concentrado, o que significa que um efeito aditivo é esperado (Rearte \& Pieroni, 2001). Entretanto, no tratamento $S 1,0$ a taxa de adição foi nula, com incremento de apenas $7,7 \%$ no ganho de peso médio diário (GMD) dos animais em relação aos animais nãosuplementados. A taxa de adição e incremento no GMD nos tratamentos S0,5 e S1,5 foram de 60 e 19\%; 53,3 e $24,6 \%$, respectivamente. O GMD médio das bezerras SS, S0,5, S1,0 e S1,5 foi, respectivamente, de 0,751; 0,894; 0,809 e 0,936 kg/animal/dia (Pilau et al., 2004).

Não houve diferença significativa no TP para grupo genético entre níveis de suplementação. A análise da variância revelou efeito da interação $(\mathrm{P}<0,05)$, avaliada por análise de regressão, entre nível de suplemento, grupo genético e período de observação (Tabela 5).

No período de 30 a 31/08, a regressão não foi significativa para TP $(\mathrm{P}>0,05)$, que apresentou média de 423,72; 409,97 e 441,22 minutos, respectivamente, para animais Charolês, 3/4 Charolês/Nelore e 5/8 Nelore/Charolês. As médias de TP, nos quatro períodos, para as bezerras Charolês, 3/4 Charolês/Nelore e 5/8 Nelore/Charolês foram, respectivamente, de 420,79; 397,15 e 410,37 minutos, com o tempo médio de pastejo das bezerras da raça Charolês inferior aos 618 minutos encontrado por Machado Filho (1990), para um período de 24 horas. Erlinger et al. (1990) observaram diferenças no tempo de pastejo diário de novilhas de diferentes grupos genéticos, com maior tempo de pastejo para animais pertencentes aos grupos de maiores pesos à maturidade.

Os coeficientes de determinação das equações foram maiores no final do ciclo das forrageiras, que apresentaram reduções de 102,18, 56,5 e 96,05 minutos no tempo de pastejo das bezerras Charolês, 3/4 Charolês/ Nelore e 5/8 Nelore/Charolês, respectivamente, para cada aumento no nível de suplementação utilizado.

O tempo de ócio não foi influenciado pelos níveis de suplemento ( $\mathrm{P}>0,05)$ com média 592,99 minutos, contrariando os relatos de Patiño Pardo et al. (2003), que, em observações diurnas de comportamento animal, notaram que animais não-suplementados diminuíram o tempo de descanso, enquanto os animais que receberam suplementação energética a $1,5 \%$ do PV apresentaram

Tabela 5 - Equações de regressão e coeficientes de determinação para tempo de pastejo de novilhas de corte de três grupos genéticos, recebendo diferentes níveis de suplementação

Table 5 - Regression equations and coefficient of determination for grazing time of beef heifers from three genetic groups receiving different energy supplementation

\begin{tabular}{|c|c|c|}
\hline \multirow{3}{*}{$\begin{array}{l}\text { Período } \\
\text { Period }\end{array}$} & \multicolumn{2}{|c|}{$\begin{array}{l}\text { Grupo genético } \\
\text { Genetic group }\end{array}$} \\
\hline & $\begin{array}{l}\text { Equação de regressão } \\
\text { Regression equation }\end{array}$ & $\mathrm{R}^{2}$ \\
\hline & $\begin{array}{l}\text { Charolês } \\
\text { Charolais }\end{array}$ & \\
\hline 03 e $04 / 08$ & $Y=594,97-67,50 x$ & 0,52 \\
\hline 30 e $31 / 08$ & $X=423,72$ & \\
\hline 27 e $28 / 09$ & $Y=594,97-67,50 x$ & 0,52 \\
\hline $31 / 10$ e $01 / 11$ & $\begin{array}{l}\mathrm{Y}=717,47-102,18 \mathrm{x} \\
\text { 3/4 Charolês/Nelore } \\
\text { 3/4 Charolais/Nellore }\end{array}$ & 0,84 \\
\hline 03 e $04 / 08$ & $Y=539,97-56,50 x$ & 0,40 \\
\hline 30 e $31 / 08$ & $X=409,97$ & \\
\hline 27 e $28 / 09$ & $Y=539,97-56,50 x$ & 0,40 \\
\hline $31 / 10$ e $01 / 11$ & $\begin{array}{l}\mathrm{Y}=669,97-56,50 \mathrm{x} \\
5 / 8 \text { Nelore/Charolês } \\
5 / 8 \text { Nellore/Charolais }\end{array}$ & 0,92 \\
\hline 03 e $04 / 08$ & $Y=502,46-48,00 x$ & 0,44 \\
\hline 30 e $31 / 08$ & $X=441,22$ & \\
\hline 27 e $28 / 09$ & $Y=502,46-48,00 x$ & 0,44 \\
\hline $31 / 10$ e $01 / 11$ & $Y=674,22-96,05 x$ & 0,90 \\
\hline
\end{tabular}

$\mathrm{x}=$ cada aumento no nível de suplemento.

$x=$ each increase in the supplement level. 
maior tempo de descanso. Este resultado pode ser decorrente da diferença entre pastagens (campo nativo x aveia+azevém) e dos períodos distintos de observação do comportamento animal, 24 horas, no presente trabalho, e apenas no período diurno no experimento conduzido por Patiño Pardo et al. (2003).

Consta na Figura 2 a distribuição do tempo de ruminação (TR) no decorrer do dia de animais recebendo diferentes níveis de suplementação.

Foi encontrada interação entre níveis de suplementação e horários, não havendo interação entre níveis de suplementação e períodos $(\mathrm{P}<0,05)$, sendo o TR em média 393 minutos. Houve diferença para TR na média dos horários $(\mathrm{P}<0,05)$, sendo maior de 18 à $6 \mathrm{~h}$, intermediário de 6 a 12 h e menor das 12 à $18 \mathrm{~h}$. Gordon \& McAllister (1970) também constataram atividade de ruminação mais consistente durante a madrugada.

A interação entre tratamentos e períodos para tempo de permanência no cocho (TC) não foi significativa ( $\mathrm{P}>0,05$; Tabela 6$)$. Houve diferença para TC entre períodos de avaliação e entre os valores médios dos níveis de suplementação $(\mathrm{P}<0,05)$. Na média dos níveis de suplementação, animais que receberam suplemento a $1,5 \%$ do PV apresentaram maior TC que animais que receberam suplemento a $0,5 \%$ e $1,0 \%$ do $\mathrm{PV}(\mathrm{P}<0,05)$. Na média dos períodos, animais-testes apresentaram maior TC no terceiro período, tempo

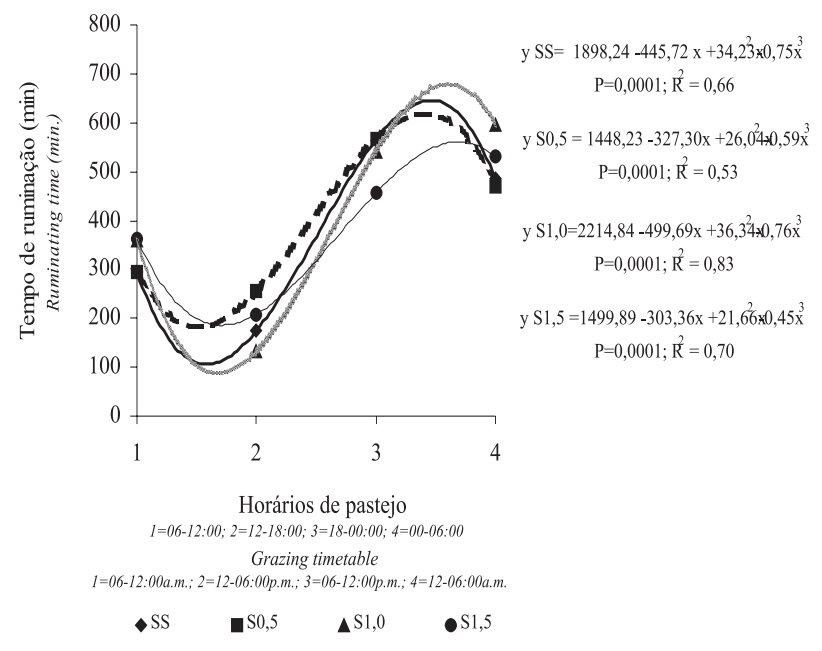

Figura 2 - Tempo de ruminação (minutos) de novilhas de corte submetidas a níveis de suplementação em pastagem de aveia preta (A. strigosa) + azevém (L. multiflorum) de acordo com os horários de pastejo.

Figure 2 - Ruminating time (minutes) of beef heifers submitted to different levels of supplementation of oat ( $A$. strigosa) and Italian ryegrass (L. multiflorum) pasture, according the grazing timetable. intermediário no primeiro período e menor TC no segundo e quarto períodos de avaliação do comportamento animal (Tabela 6). No primeiro período, o TC foi intermediário provavelmente pela adaptação e aquisição de confiança das bezerras em relação ao horário da suplementação, pois, antes deste experimento, recebiam suplementação volumosa em outro horário. No segundo período, o maior consumo estimado de forragem (Tabela 3 ) pode ter sido um dos motivos da redução do TC. No terceiro período, o expressivo TC apresentado pelos animais que receberam suplemento a $1,5 \%$ do PV refletiu em maior TC na média dos períodos. No quarto período, ou seja, no final do ciclo das forrageiras, a elevada proporção de colmos nas forrageiras pode ter sido resultante da maior disputa entre animais pelo consumo de suplemento, resultando em menor TC.

O TC diferiu entre os níveis de suplementação no terceiro e quarto períodos de avaliação $(\mathrm{P}<0,05)$. No terceiro período, os animais apresentaram maior TC no tratamento $S 1,5$, enquanto, no quarto período, os animais do tratamento S1,5 apresentaram maior TC que os do tratamento $\mathrm{S} 0,5$, não diferindo dos animais do tratamento $\mathrm{S} 1,0(\mathrm{P}<0,05)$. No primeiro e segundo períodos, não houve diferença entre os tratamentos para TC $(\mathrm{P}>0,05)$.

Houve interação $(\mathrm{P}=0,0001)$ entre níveis de suplementação e horários (Tabela 7), com maiores TC nos horários de 12 às 18 h, e quando os animais foram suplementados com 1,0 e 1,5\% do PV (Tabela 7). Neste mesmo horário, o TC dos animais suplementados com $0,5 \%$ do PV foi intermediário. Nos demais períodos, animais recebendo suplemento em diferentes níveis não diferiram no TC $(\mathrm{P}>0.05)$.

Os valores médios do número de refeições diárias (ou visitas ao cocho) e tempo médio por refeição, em minutos, são apresentados na Tabela 8 . O número de refeições diárias foi influenciado pelos níveis de concentrado e pelo tempo despendido por refeição. Um efeito linear decrescente para o tempo despendido por refeição, em função dos níveis de concentrado, também foi observado por Bürger et al. (2000).

$\mathrm{O}$ retorno ao cocho foi mais freqüente com o aumento dos níveis de suplemento, entretanto, o tempo de permanência no cocho diminuiu. A ingestão muito rápida de grande quantidade de suplemento de uma só vez poderia provocar distúrbios digestivos nos animais, pois o declínio no $\mathrm{pH}$ ruminal, associado ao aumento do amido na dieta afetam as bactérias ruminais, resultando na redução da digestão da fibra e do consumo de forragem no pastejo (Caton \& Dhuyvetter, 1997). 
Tabela 6 - Médias estimadas do tempo de permanência no cocho (minutos) de bezerras de corte recebendo diferentes níveis de suplemento em pastagem de aveia ( $A$. strigosa) e azevém (L. multiflorum), em quatro períodos de observação

Table 6 - Estimated means of trough stay time (minutes) of beef heifers receiving different levels of supplement in oat (A. strigosa) and Italian ryegrass (L. multiflorum) in four periods of observation

\begin{tabular}{|c|c|c|c|c|c|}
\hline \multirow{5}{*}{$\begin{array}{l}\text { Tratamento } \\
\text { Treatment }\end{array}$} & \multicolumn{4}{|c|}{$\begin{array}{l}\text { Taxa de permanência no cocho } \\
\text { Trough stay time }\end{array}$} & \multirow{5}{*}{$\begin{array}{l}\text { Média } \\
\text { Mean }\end{array}$} \\
\hline & \multirow{2}{*}{\multicolumn{4}{|c|}{$\begin{array}{l}\text { Período } \\
\text { Period }\end{array}$}} & \\
\hline & & & & & \\
\hline & $03 \mathrm{e}$ & $30 \mathrm{e}$ & $27 \mathrm{e}$ & $31 / 10 \mathrm{e}$ & \\
\hline & 04/08 & $31 / 08$ & 28/09 & 01/11 & \\
\hline S0,5 & 31,66 & 41,66 & $44,99 b$ & $19,99 b$ & $34,58 b$ \\
\hline $\mathrm{S} 1,0$ & 81,66 & 34,99 & $68,33 b$ & $38,32 \mathrm{ab}$ & $55,83 \mathrm{~b}$ \\
\hline $\mathrm{S} 1,5$ & 88,31 & 49,99 & $124,98 \mathrm{a}$ & $69,98 \mathrm{a}$ & $83,32 \mathrm{a}$ \\
\hline Média & $67,21 \mathrm{ab}$ & $42,21 b$ & $79,43 a$ & $42,76 b$ & \\
\hline Mean & & & & & \\
\hline
\end{tabular}

Médias, na mesma linha, seguidas por letras distintas, diferem $(P<0,05)$ pelo teste $F$.

Means, in the same line, with distinct letters, differ $(P<.05)$ by $F$ test.

Tabela 7 - Médias estimadas do tempo de permanência no cocho (minutos) de bezerras de corte recebendo diferentes níveis de suplemento em pastagem de aveia (A. strigosa) e azevém (L. multiflorum) no decorrer do dia

Table 7 - Estimated means (minutes) of beef heifers receiving different levels of supplement in oat ( $A$. strigosa) and Italian ryegrass (L. multiflorum) pasture during the day

\begin{tabular}{|c|c|c|c|c|c|}
\hline \multirow{4}{*}{$\begin{array}{l}\text { Tratamento } \\
\text { Treatment }\end{array}$} & \multicolumn{4}{|c|}{$\begin{array}{l}\text { Taxa de permanência no cocho } \\
\text { Trough stay time }\end{array}$} & \multirow{4}{*}{$\begin{array}{l}\text { Total } \\
\text { Total }\end{array}$} \\
\hline & \multirow{2}{*}{\multicolumn{4}{|c|}{$\begin{array}{l}\text { Horário } \\
\text { Timetable }\end{array}$}} & \\
\hline & & & & & \\
\hline & 06-12 & $12-18$ & $18-24$ & 24-06 & \\
\hline S0,5 & 0,00 & 32,91 & 0,42 & 1,25 & $34,58 b$ \\
\hline $\mathrm{S} 1,0$ & 2,50 & 48,33 & 5,00 & 0,00 & $55,83 \mathrm{~b}$ \\
\hline $\mathrm{S} 1,5$ & 8,33 & 52,91 & 10,42 & 11,67 & $83,32 \mathrm{a}$ \\
\hline Média & $2,71 b$ & $33,54 a$ & $3,96 b$ & $3,23 b$ & \\
\hline Mean & & & & & \\
\hline
\end{tabular}

Médias, na mesma linha, seguidas por letras distintas, diferem $(P<0,05)$ pelo teste $F$. $M e a n s$, in the same line, with distinct letters, differ $(P<.05)$ by $F$ test.

Tabela 8 - Freqüência de retorno ao cocho (vezes/dia) e média de tempo de permanência no cocho de bezerras recebendo níveis crescentes de suplementação

Table 8 - Frequency of trough return (times/day) and mean of trough stay time of beef heifers receiving crescent levels of supplementation

\begin{tabular}{lcc}
\hline $\begin{array}{l}\text { Tratamento } \\
\text { Treatment }\end{array}$ & $\begin{array}{c}\text { Freqüência de retorno ao cocho } \\
\text { Frequency of trough return }\end{array}$ & $\begin{array}{c}\text { Tempo de permanência no cocho } \\
\text { Trough stay time }\end{array}$ \\
\hline S0,5 & 3 & $10 \mathrm{~min} 42 \mathrm{~s}$ \\
S1,0 & 6 & $8 \mathrm{~min} 32 \mathrm{~s}$ \\
S1,5 & 9 & 7 min $50 \mathrm{~s}$ \\
\hline
\end{tabular}


Portanto, a suposição de que seria necessário o aumento na frequiência do fornecimento de suplemento, proporcionando acréscimo de mão de obra, não é verdadeira quando o farelo de trigo é fornecido como fonte energética, pois o aumento da frequiência é realizado pelos próprios animais, que não consomem o alimento fornecido de uma só vez.

\section{Conclusões}

Animais suplementados diminuem o tempo de pastejo em relação aos não-suplementados, mas sem alteração no consumo estimado de forragem.

Animais que recebem suplementação de farelo de trigo a $1,5 \%$ do PV permanecem mais tempo no cocho e a freqüência de retorno ao cocho é maior com o aumento dos níveis de suplementação.

A suplementação não interfere nos tempos de ruminação e ócio.

\section{Literatura Citada}

AD AMS, D.C. Effect of time of supplementation on performance, forage intake and grazing behavior of yearling beef grazing Russian roildrygrass in the fall. Journal of Animal Science, v.61, n.4, p.1037-1042, 1985.

ASSOCIATION OF OFFICIAL ANALYTICAL CHEMISTS AOAC. Official methods of analysis. 14.ed. Washington, D.C.: 1984. 1141p.

BOMFIM, M.A.D.; REZENDE, C.A.P.; PAIVA, P.C.A. et al. Efeito do nível de concentrado no tempo de pastejo de novilhos holandês x zebu suplementados a pasto na estação seca. In: REUNIÃO ANUAL DA SOCIEDADE BRASILEIRA DE ZOOTECNIA, 37., 2000, Viçosa, MG. Anais... Viçosa, MG: Gnosis, 2000, 488 par. CD-ROM. Bioclimatologia e Etologia. ETO-0488.

BÜRGER, P.J.; PEREIRA, J.C.; QUEIROZ, A.C. et al. Comportamento ingestivo em bezerros holandeses alimentados com dietas contendo diferentes níveis de concentrado. Revista Brasileira de Zootecnia, v.29, n.1, p.236-242, 2000.

CATON, J.S.; DHUYVETTER, D.V. Influence of energy supplementation on grazing ruminants: requirements and responses. Journal of Animal Science, v.75, n.4, p.533-542, 1997.

CHACON, E.; STOBBS, T.H.; SANDLANDS, R.L. Estimation of herbage comsumption by grazing cattle using measurements of eating behavior. Journal of British Grassland Society, v.31, p.81-85, 1976.

ERLINGER, L.L.; TOLLESON, D.R.; BROWN, C.J. Comparison of bite size, biting rate and grazing time of beef heifers from herds distinguished by mature size and rate of maturity. Journal of Animal Science, v.68, p.3578-3587, 1990.

EUCLIDES, V.P.B. Quality evaluation and cattle grazing behavior on bahiagrass and limpograss pastures. Gainesville: University of Florida, 1985. 176p. Thesis (Doctor of Philosophy) - University of Florida, Gainesville, 1985.
EUCLIDES, V.P.B.; MACEDO, M.C.M.; OLIVEIRA, M.P. Avaliação de diferentes métodos de amostragem sob pastejo. Revista Brasileira de Zootecnia, v.21, n.4, p.691-702, 1992.

FORBES, T.D.A. Researching the plant-animal interface: the investigation of ingestive behavior in grazing animals. Journal of Animal Science, v.66, p.2369-2379, 1988.

FORCHERIO, J.C.; PATERSON, J.A.; KERLEY, M.S. Effect of source of supplemental energy and level of undegradable protein on forage intake and performance of cow-calf pairs grazing endophyte-infected tall fescue pasture. Journal of Animal Science, v.70 (Suppl. 1), p.188 (Abstr.), 1992.

GALLI, J.R.; CANGIANO, C.A.; FERNÁNDEZ, H.H. Comportamiento ingestivo y consumo de bovinos en pastoreo. Revista Argentina de Produção Animal, v.16, n.2, p.119-142, 1996.

GIBB, M.J.; TREACHER, T.T. The effect of herbage allowance on herbage intake and performance of lambs grazing perennial ryegrass and red clover swards. Journal of Agricultural Science, v.86, p.355-365, 1976.

GORDON, J.G.; Mc ALLISTER, I.K. The circadian rhythm of rumination. Journal of Agricultural Science, v.74, n.2, p.291-297, 1970.

HANCOCK, J. Grazing behaviour of cattle. Animal Breeding Abstract, v.21, n.1, p.1-13, 1953.

HESS, B.W.; KRYSL, L.J.; JUDKINS, M.B. et al. Supplementation of cattle grazing dormant intermediate wheatgrass pasture. Proceedings... Western Section American Society of Animal Science, 1992. p.43-70.

HILLESHEIM, A. Fatores que afetam o consumo e perdas de capim-elefante (Pennisetum purpureum Schum.) sob pastejo. Piracicaba: Escola Superior da Agricultura Luiz de Queiroz, 1997. 94p. Dissertação (Mestrado em Zootecnia) Escola Superior da Agricultura Luiz de Queiroz, 1997.

HODGSON, J. Ingestive behavior. In: LEAVER, J.D. (Ed.) Herbage intake handbook. Hurley: British Grassland Society, 1982. p.113.

HODGSON, J. Grazing management. Science into practice. London: Longman Scientific \& Technical, 1990. p.203.

JAMIESON, W.S.; HODGSON, J. The effect of daily herbage allowance and sward characteristics upon the ingestive behavior of calves under strip-grazing management. Grass and Forage Science, v.34, p.261-271, 1979a.

JAMIESON, W.S.; HODGSON, J. The effect of variation in sward characteristics upon the ingestive behavior and herbage intake of calves and lambs under continuous stocking management. Grass and Forage Science, v.34, p.273-281, 1979b.

KARSLI, M.A. Grazing behavior of ruminant livestock. 2001. <www.agron.iastate.edu/moore/434/chapter6htm> 04-05-2001.

KLINGMANN, D.L.; MILES, S.R.; MOTT, G.O. The cage method for determining consumption and yield of pasture herbage. Journal of Society of Agronomy, v.35, p.739-746, 1943.

KRYSL, L.J.; HESS, B.W. Influence of supplementation on behavior of grazing cattle. Journal of Animal Science, v.71, p.2546-2555, 1993.

MACHADO FILHO, L.C.P.; TENNESSEN, T.; QUADROS, F.F. et al. Avaliação do comportamento de pastoreio do gado Crioulo Lageano, Charolês e Nelore em campo nativo. In: 
REUNIÃO ANUAL DA SOCIEDADE BRASILEIRA DE ZOOTECNIA, 27., 1990, Campinas. Anais...Campinas: Sociedade Brasileira de Zootecnia, 1990. p.366.

MORENO, J.A. Clima do Rio Grande do Sul. Porto Alegre: Secretaria da Agricultura, 1961. 41p.

MOTT, G.O.; LUCAS, H.L. The design, conduct, and interpretation of grazing trials in cultivated and improved pastures. In: INTERNATIONAL GRASSLAND CONGRESS, 6., 1952, State College. Proceedings... State College: Pensylvania, State College Press, 1952. p.1380-1385.

NARDON, R.F.; LOBATO, J.P.F.; COELHO JR., W. O pastejo diurno de novilhas de corte, manejadas em pastagens subtropicais no verão. In: REUNIÃO ANUAL DA SOCIEDADE BRASILEIRA DEZOOTECNIA, 24., 1987, Brasília. Anais... Brasília: Sociedade Brasileira de Zootecnia, 1987. p.235.

NATIONAL RESEARCH COUNCIL - NRC. Nutrient requirement of beef cattle. 7.ed. Washington, D.C.: National Academy Press, 1996. 242p.

PATIÑO PARDO, N.M.; FISCHER, V.; BALBINOTTI, M. et al. Comportamento ingestivo diurno de novilhos em pastejo submetidos a níveis crescentes de suplementação energética. Revista Brasileira de Zootecnia, v.32, n.6, p.1408-1418, 2003.

PILAU, A.; ROCHA, M.G.; RESTLE, J. et al. Recria de novilhas de corte com diferentes níveis de suplementação energética em pastagem de aveia preta e azevém. Revista Brasileira de Zootecnia, v.33, n.6 (supl. 1), p.2104-2113, 2004.

POLI, C.H.E.C.; ROCHA, M.G.; PIRES, C.C. et al. The effect of feed supplementation and sward characteristics on the ingestive behavior of grazing ewes. In: INTERNATIONAL GRASSLAND CONGRESS, 19., 2001, São Pedro. Proceedings... CD-ROM-Papers: ID 07-13. Prod. Macromedia.

POLLI, V.A.; LOBATO, J.F.P. Comportamento de bovinos de corte. I. Vacas de corte. In: REUNIÃO ANUAL DA SOCIEDADE BRASILEIRA DE ZOOTECNIA, 21., 1984, Belo Horizonte. Anais... Belo Horizonte: Sociedade Brasileira de Zootecnia, 1984. p.109.
REARTE, D.H.; PIERONI, G.A. Supplementation of temperate pastures. In: INTERNATIONAL GRASSLAND CONGRESS, 19., 2001, São Pedro. Proceeding... São Pedro: Sociedade Brasileira de Zootecnia, 2001. p.679-689.

ROCHA, M.G. Suplementação a campo de bovinos de corte. In: LOBATO, J.F. (Ed.) Produção de bovinos de corte. Porto Alegre: PUCRS, 1999. p.77-96.

STATISTICAL ANALYSES SYSTEM - SAS. User's guide. Version 6.08. Cary: 1996. 1014p.

STOBBS, T.H. Automatic measurement of grazing time by dairy cows on tropical grass and legume pasture. Tropical Grassland, v.4, n.2, p.237, 1970.

STOBBS, T.H. The effect of plant structure on the intake of tropical pastures. 1. Variation in the bite size of grazing cattle. Australian Journal of Agricultural Research, v.24, p.809-19, 1973.

SUNVOLD, G.D.; COCHRAN, R.C.; VANZANT, E.S. Evaluation of wheat middlings as a supplement for beef cattle consuming dormant bluestem-range forage. Journal of Animal Science, v.69, p.3044-3054, 1991.

TILLEY, J.M.A.; TERRY, R.A. A two-stage technique for the in vitro digestion of forage crop. Journal of British Grassland Society, v.18, n.2, p.104-111, 1963.

WILM, H.G.; COSTELLO, D.F.; KLIPPLE, G.E. Estimating forage yield by the double-sampling methods. Journal of American Society of Agronomy, v.36, p.194-203, 1944.

Recebido em: 12/02/04

Aceito em: 06/12/04 